\title{
The economic drivers of commodity market volatility
}

Article

Accepted Version

Creative Commons: Attribution-Noncommercial-No Derivative Works 4.0

Prokopczuk, M., Stancu, A. and Symeonidis, L. (2019) The economic drivers of commodity market volatility. Journal of International Money and Finance, 98. 102063. ISSN 02615606 doi: https://doi.org/10.1016/j.jimonfin.2019.102063 Available at https://centaur.reading.ac.uk/85173/

It is advisable to refer to the publisher's version if you intend to cite from the work. See Guidance on citing.

To link to this article DOI: http://dx.doi.org/10.1016/j.jimonfin.2019.102063

Publisher: Elsevier

All outputs in CentAUR are protected by Intellectual Property Rights law, including copyright law. Copyright and IPR is retained by the creators or other copyright holders. Terms and conditions for use of this material are defined in the End User Agreement.

\section{www.reading.ac.uk/centaur}

\section{CentAUR}

Central Archive at the University of Reading

Reading's research outputs online 


\title{
The Economic Drivers of Commodity Market Volatility*
}

\author{
Marcel Prokopczuk ${ }^{\dagger, \ddagger}$, Andrei Stancu ${ }^{\S}$
}

and

\section{Lazaros Symeonidis $\mathbb{I}$}

\begin{abstract}
We analyze the relationship between economic uncertainty and commodity market volatility. We find that commodity market volatility comoves strongly with economic and financial uncertainty, especially during recessions. Variables associated with credit risk, financial market stress and fluctuations in business conditions bear significant predictive ability for commodity market volatility. The documented predictability is mainly observed in the period after the financialization of commodity markets (i.e. post-2004) and it peaks during the 2008-2009 global financial crisis.
\end{abstract}

\section{JEL classification: G12, G13}

Keywords: Commodities, Economic Uncertainty, Volatility, Financialization, Crisis.

${ }^{*}$ We thank Chris Brooks, Mike Clements, Richard Harris, Peter Moffatt, David Simon, Jean-Guy Simonato and Chardin Wese Simen for helpful comments on an earlier draft of this paper. We are particularly grateful to Claudio Morana, Bradley Paye, and William Schwert for clarifications on their related research. We also thank the participants in the 23rd Annual Derivatives Securities and Risk Management Conference, the 2013 Financial Management Association European Conference, the 2013 European Financial Management Association Meetings, the 2013 World Finance Conference, the 2013 Financial Management Association Meetings, the $12^{\text {th }}$ Conference on Research on Economic Theory and Econometrics, the 2014 International Association for Applied Econometrics Annual Conference, the 2016 Energy and Commodity Finance Conference, the 2016 World Finance Conference and the seminar participants at Zeppelin University and the University of East Anglia for useful comments. Previous versions of this paper were circulated under the title: "On the Economic Sources of Commodity Market Volatility".

†Leibniz University Hannover, Koenigsworther Platz 1, D-30167 Hannover, Germany. Contact: prokopczuk@fmt.uni-hannover.de

${ }^{\ddagger}$ ICMA Centre, Henley Business School, University of Reading, RG6 6BA, UK

$\S$ Norwich Business School, University of East Anglia, Norwich NR4 7TJ, United Kingdom. Contact: a.stancu@uea.ac.uk

${ }^{\mathbb{I} N o r w i c h ~ B u s i n e s s}$ School, University of East Anglia, Norwich NR4 7TJ, UK. Contact: l.symeonidis@uea.ac.uk (corresponding author) 


\section{Introduction}

Commodity price volatility is a direct input in hedging, risk management, and commodity contingent claim valuation. Furthermore, it affects production decisions through its impact on the value of the option embedded in inventory. Therefore, understanding the sources of its variations is an issue of paramount importance for investors, producers and policy makers. In this paper, we are seeking to fill a substantial gap in the literature by empirically investigating whether countercyclical variations in commodity market volatility can be explained by variables related to economic uncertainty.

Following the seminal paper of Schwert (1989), a large number of studies have attempted to answer the above question in the context of equity and bond markets, using different variables and econometric methodologies (Hamilton and Lin, 1998; Ludvigson and Ng, 2009; Paye, 2012; Engle et al., 2013). Despite their economic importance, commodities have attracted much less attention in the existing literature. We argue that investigating the links between economic uncertainty and commodity market volatility has profound implications in light of recent developments in commodity markets, such as the impact of index fund investments and the financialization of commodity markets (Tang and Xiong, 2012; Singleton, 2014) as well as the increased trading activity in liquid commodity volatility instruments, such as commodity variance swaps.

Using an extensive dataset of daily futures prices on 25 major commodities we construct an equally-weighted excess return commodity market index as well as equally-weighted sectoral sub-indices. In addition, we consider the S\&P GSCI index for our analysis as the most popular benchmark of commodity investment performance. Our investigation leads to a number of novel findings. We first 
document a countercyclical variation in commodity futures volatility. Extending the evidence of Gorton and Rouwenhorst (2006) and Gargano and Timmermann (2014) from commodity returns, we find that commodity market volatility comoves with economic and financial uncertainty. This temporal dependence is much stronger during recessions than during expansions.

We then explore whether commodity market volatility can be predicted using a set of theoretically motivated variables associated with time-varying risk and changing investment opportunities. In particular, we investigate whether these variables contain information beyond that embedded in lagged volatility. We place our emphasis on two sub-samples of the January 1990-December 2015 period that are of particular importance, namely pre- and post-financialization of commodity markets (Tang and Xiong, 2012). We show that variables associated with credit risk (e.g. default return), funding liquidity (e.g. TED spread), equity and bond market stress (e.g. VIX and implied volatility of treasury bonds), and fluctuations in real business conditions bear significant predictive power over commodity market volatility. Furthermore, a combination of significant variables delivers a forecast improvement relative to a simple autoregressive benchmark of about 5\%. Most importantly, we identify a structural change in the predictive ability of the above risk factors after the financialization of commodity markets (i.e. after 2004). Consistent with the extensive evidence on the heterogeneity of commodities (Erb and Harvey, 2006), we observe some differences in the exposure of the various commodity sectors to the risk factors considered.

Moreover, to investigate potential time-variation in the predictive power of the different variables we analyze the dynamics of predictability in a rolling regression context. Our results show that the documented predictability is to a great extent concentrated in the 2008-2009 global financial crisis period. Most 
notably, a simple combination of predictors offers substantial gains in predictive performance, with an an increase in the adjusted $R^{2}$ as high as $12 \%$ in the period following the outburst of the global financial crisis. This result is consistent with recent research on equity markets which shows that predictability is time-varying and is concentrated in bad times (e.g., Henkel et al., 2011).

Our work primarily adds to the strand of the asset pricing literature that deals with volatility prediction using economic variables (Schwert, 1989; Beltratti and Morana, 2006; Engle et al., 2013). In a study related to ours, Paye (2012) finds that several variables have predictive power over aggregate stock market volatility, especially at the quarterly horizon. However, the forecasting ability of these variables is relatively limited out-of-sample. The study probably most closely related to ours is Gargano and Timmermann (2014), who employ economic variables to predict commodity returns. We complement their evidence in the following ways. First, in contrast to Gargano and Timmermann (2014), who place their focus on predicting commodity returns, we perform a comprehensive analysis of commodity futures' volatility prediction, reaching additional new results. Second, we identify novel risk factors that appear to drive commodity market volatility, such as the default return spread, the TED spread, the VIX, and the option implied volatility of US treasury bonds. ${ }^{1}$

We also add to the commodity pricing literature. Most existing studies on the determinants of commodity price volatility deal with factors that are specific to commodities, such as the convenience yield (Geman and Nguyen, 2005; Gorton et al., 2013) or hedging pressure (Bessembinder, 1992; De Roon et al., 2000). Furthermore, studies that explore the role of economic variables mainly focus on commodity returns (Bailey and Chan, 1992; Hong and Yogo,

\footnotetext{
${ }^{1}$ Our work is also related to the literature that studies spillovers between commodities and other asset classes (e.g., Creti et al., 2013; Degiannakis and Filis, 2017).
} 
2012; Issler et al., 2014; Ornelas and Mauad, 2017) rather than volatility. There are very few studies to date which seek to explore the link between economic uncertainty and commodity market volatility (Christiansen et al., 2012, e.g.,). Therefore, the results of our study are expected to provide important input for risk management in commodity markets as its effectiveness heavily depends on accurate measurement of risk.

The remainder of this paper is organized as follows. In Section 2 we describe the data and variables employed for our empirical analysis. In Section 3 we present and discuss our results and main findings. Finally, Section 4 concludes.

\section{Data and Variables}

In this section we discuss the data and variables used in our analysis. We start by describing the equally-weighted excess return commodity futures index and its sectoral sub-indices. A more detailed analysis is presented in section A.1 of the online appendix. We then introduce the macroeconomic and financial risk factors employed in our subsequent analysis.

\subsection{Commodity Futures Returns}

Our dataset consists of daily prices on 25 commodity futures traded in the US. The data are obtained from the Commodity Research Bureau (CRB) and cover the period from January 1, 1970 to December 29, 2015. ${ }^{2,3}$ We employ futures

\footnotetext{
${ }^{2}$ The earliest recorded futures prices in the CRB database are reported in July 1959. However, those only include some agricultural commodities. Moreover, the historical data for the S\&P GSCI index that we also use in our analysis starts in January 1970.

${ }^{3}$ The empirical results presented in Section 3 are based on the period from January 1990 to December 2015. This period is chosen based on the greater availability and better quality of commodity futures' price data. For instance, the sample of most energy futures begins between the late 1980s to the early 1990s (e.g. natural gas). Moreover, some of the variables used in our analysis are available from the 1990s onwards (e.g. the VIX).
} 
rather than physical spot prices because the former correspond to real transaction prices. The commodities in our sample can be classified into four broad categories, namely: (i) Agricultural, (ii) Livestock, (iii) Energy, and (iv) Metals. Table 1 contains details on the commodity futures dataset.

We start by computing daily excess returns for each commodity futures following Singleton (2014). We employ the prices of the nearest and second nearest to maturity futures contracts, respectively (typically those are the most liquid ones). We assume a rollover strategy that takes a long position to the nearest to maturity futures contract which is closed out on the last trading day prior to the delivery month and then a new long position to the next nearest to maturity contract is opened. The procedure is described in more detail in section A.1 of the online appendix. We then construct an equally-weighted excess return index of commodity futures as an equally-weighted average of the daily excess returns across all the 25 commodities. ${ }^{4}$ We apply the same logic to create equally-weighted sub-indices for each of the four broad commodity sectors, namely: agricultural, livestock, energy, and metals.

In order to ensure that our empirical findings are not driven by the specific equally-weighted commodity index, we also consider the S\&P GSCI Excess Return Index for our analysis, which is the most popular commodity price benchmark. However, the over-weighting of energy in the GSCI index is likely to create a bias towards the energy sector. To address this concern, we take the average across returns of its four main excess return sub-indices (i.e. agricultural, energy, livestock and metals). We denote this index GSCI(Eq) to distinguish it from the standard S\&P GSCI index.

\footnotetext{
${ }^{4}$ Note that the number of commodities included in the index changes over time, depending on the availability of futures' price data. Therefore, the index starts with 14 commodities in 1970 and ends up with 25 in 2015 . The index includes the full set of 25 commodities after the early 1990 s.
} 


\section{$2.2 \quad$ Economic Predictors}

To construct economic risk proxies we first consider variables that reflect changes in the state of the broader economy. In particular, we gather data on: the growth rate of the Consumer Price Index (Inflation), the growth rate in industrial production $(I P)$, the growth rate in the M2 money supply measure (M2), the Chicago Fed National Activity Index (CFNAI), the return on the trade-weighted US dollar index (USD index) against major currencies, and the Aruoba-Diebold-Scott Business Conditions Index (ADS) of Aruoba et al. (2009), which is constructed to track real economic activity at a high-frequency level. All series with the exception of the ADS index, are obtained from the Federal Reserve Bank of St. Louis (FRED). The first four series are available at a monthly frequency, whereas the USD index is sampled daily. Monthly data on the ADS index is collected from the website of the Federal Reserve of Philadelphia.

We also consider a set of variables that are associated with changing financial market conditions and covary with the business cycle. Also, from a theoretical standpoint, these variables represent shifts to the investment opportunity set in the context of asset pricing theories, such as the intertemporal capital asset pricing model of Merton (1973). Specifically, we employ: the default yield spread (difference between Moody's Baa and Aaa corporate bond yields), the term spread (long-term government bond yield minus the 3-month T-bill yield), the default return spread (difference between the long-term corporate and the long-term government bond returns), and the TED spread (difference between the 3-month LIBOR rate and the 3-month T-bill yield). All these series are obtained from FRED, except for the long-term corporate and government bond returns that are collected from the webpage of Amit Goyal.

Finally, we consider three risk measures related to equity and bond market 
stress and may also be viewed as general economic uncertainty proxies. The first one is the Merrill Lynch 1-month Bond Volatility Index (MOVE1M), which is the month-ahead expectation of volatility extracted from at-the-money US Treasury bond options. The second one is the end-of-month level of the VIX index, which corresponds to the risk-neutral expectation of the next 30-day volatility extracted from the prices of out-of-the-money call and put options on the S\&P 500 index. The last variable is the variance risk premium $(V R P)$ of the S\&P 500 index defined as the spread between risk-neutral and physical expectations of variance (Carr and $\mathrm{Wu}, 2009)$, i.e.: $V R P_{t}=V I X_{t}^{2}-E_{t}\left(R V a r_{t+1}\right)$, where: $V I X_{t}$ is the option implied volatility of the S\&P500 index at the end of month $t$ and $E_{t}\left(R V a r_{t+1}\right)$ is the expectation of month's $t+1$ realized variance formed at time $t$. We use the realized variance of month $t, R V a r_{t}$, as the expectation of month's $t+1$ variance, similar to Zhou (2009). ${ }^{5}$ The daily realized variance series (from 5-minute returns) is directly obtained from the Oxford-Man Institute Realised Volatility Library.

Section A.2 of the online appendix describes the motivation for considering the above variables and provides a definition for each one of them.

\section{Empirical Analysis}

In this section, we first describe the methods used to obtain volatility estimates for variables observed at different frequencies. We then analyze the relationship between economic uncertainty and commodity market volatility. We begin by exploring the contemporaneous links and then we investigate predictive relationships.

\footnotetext{
${ }^{5}$ In addition, we consider variance forecasts produced from an Heterogeneous Autoregressive (HAR) model (Corsi, 2009). This choice does not change our results.
} 


\subsection{Measuring Volatility}

Following the standard approach in the volatility literature, we compute monthly commodity futures' volatility as the square root of the sum of squared daily intra-month demeaned futures returns:

$$
R V_{t}=\sqrt{\sum_{j=1}^{N_{t}}\left(r_{j, t}-\bar{r}_{t}\right)^{2}}
$$

where: $r_{j, t}$ is the excess commodity futures return on day $j$ of month $t, \bar{r}_{t}$ is the average futures excess return of month $t$, and $N_{t}$ is the number of daily return observations in month $t$. We apply this estimator for the two aggregate commodity market indices (i.e, equally-weighted and GSCI(Eq), respectively) as well as for the four sectoral sub-indices. The documented non-Gaussian behavior of realized volatility estimates (Andersen et al., 2001; Areal and Taylor, 2002) may lead to violations in the core assumptions of least squares estimation. ${ }^{6}$ To this end, we follow Paye (2012) and work with the logarithm of the annualized commodity return volatility: $L R V_{t}=\log \left(\sqrt{12} R V_{t}\right)$.

Despite its empirical appeal, the estimator of Equation (1) can only be applied to daily (or intraday) data. Nonetheless, most macroeconomic series are only available at the monthly frequency. Therefore, alternative procedures to obtain volatility estimates need to be employed. We apply a simple two-step non-parametric method similar to Schwert (1989) and Bansal et al. (2005). We start with the estimation of a twelfth-order autoregressive process on the logarithmic difference of each economic series, including dummy variables to allow

\footnotetext{
${ }^{6}$ This non-Gaussian feature of the empirical distribution of realized volatility can be seen from kernel density plots of level vs. the log of commodity market volatility, which are reported in the supplementary appendix (Figure B3). As pointed out by Andersen et al. (2003), although the distribution of raw volatility estimates is positively skewed, the distribution of logarithmic volatility is approximately normal. Our plots strongly support this conjecture.
} 
for time-variation in the intercept:

$$
Y_{t}=\sum_{i=1}^{12} a_{i} M_{i, t}+\sum_{j=1}^{12} b_{j} Y_{t-j}+e_{t}
$$

where: $Y_{t}$ is the growth rate (i.e. logarithmic difference) of a particular economic aggregate and $M_{i, t}$ are monthly dummy variables. We then obtain the logarithm of conditional volatility $\left(V_{t}\right)$ through a 12-month rolling average of the absolute values of the residuals $\left(e_{t}\right)$ from Equation $(2):^{7}$

$$
V_{t}=\log \left(\sqrt{6 \pi} \sum_{p=1}^{12}\left|e_{t-p+1}\right|\right)
$$

The above two-step procedure is applied to the series of inflation, IP, and M2 money supply. The series obtained through Equation (3) are employed as macroeconomic uncertainty proxies. Moreover, for variables sampled daily (i.e. the USD index), uncertainty measures are obtained using the realized volatility estimator of Equation (1). ${ }^{8}$

Finally, we work with the levels rather that the volatilities of the remaining variables, namely: term spread, default yield spread, default return spread, TED spread, ADS, MOVE1M, and CFNAI since they already reflect risk or variation in real economic conditions. We compute monthly averages from daily values for the series that are available at a daily frequency. ${ }^{9}$ Similarly, we employ the level of the VIX and variance risk premium series defined in the previous section.

\footnotetext{
${ }^{7}$ As mentioned in Schwert (1989), the absolute residuals from Equation (2) are scaled by $\sqrt{\pi / 2}$ since the expectation of the absolute value of the normally distributed error (equal to $\sigma \sqrt{2 / \pi}$ ) is smaller than the standard deviation of the error by a factor of $\sqrt{2 / \pi}$. Also, to annualize the volatility series, we multiply by $\sqrt{12}$, yielding the term $\sqrt{6 \pi}$.

${ }^{8}$ As a robustness check we obtain monthly volatility estimates through a $\operatorname{GARCH}(1,1)$ model fitted on monthly series of economic variables and commodity returns. The results from this alternative consideration are very similar (see section C.1 of the online appendix).

${ }^{9}$ Using end-of-month values instead of monthly averages led to extremely similar coefficient estimates in our later empirical exercise.
} 
Figure 1 plots the logarithm of the realized volatility of the equally-weighted excess return index and of the $\mathrm{GSCI}(\mathrm{Eq})$ index, respectively, for the period between January 1970 and December 2015. The shaded areas on the plot correspond to recession periods as classified by the National Bureau of Economic Research (NBER). The plot provides a first indication of the countercyclical behavior of commodity market volatility.

In order to provide more formal evidence we perform a series of regressions of commodity market volatility on a recession indicator and lags of volatility. These results are presented in section A.3 of the online appendix and suggest that the commodity market volatility is significantly higher during recessions. This finding raises the question of whether variables that comove with the business cycle can help predict the volatility of commodity futures returns.

\subsection{Comovement Analysis}

Table 2 reports summary statistics for the variables used in our empirical analysis. In line with previous studies (Schwert, 1989; Beltratti and Morana, 2006), we observe that financial variables, such as the VIX or the MOVE1M, are much more volatile than the macroeconomic variables. The first and twelfth order autocorrelation coefficients (columns labeled $\rho_{1}$ and $\rho_{12}$, respectively) indicate that most predictors are highly persistent. This slow decay is potentially related to long memory in volatility documented by several studies (e.g. Areal and Taylor, 2002). To avoid spurious results due to highly persistent dependent variables and regressors, we consider a large number of lags of the dependent variable in our 
subsequent estimations, as suggested by Paye (2006). ${ }^{10}$

Table 3 presents correlations between commodity return volatility and macroeconomic and financial risk measures. We focus our comovement analysis on the period between January 1990 and December 2015 (Panel I), first to obtain a balanced sample across most variables and second to ensure that our commodity index includes the full range of 25 commodities. ${ }^{11}$ The table shows that commodity market volatility comoves with economic uncertainty.

In Panels II and III we present pairwise correlations during NBER expansion and recession periods, respectively, over the same sample period. Comparing these coefficients in Panels II and III, we clearly see that the documented comovement is much stronger during recessions as compared to expansions. For example, the correlation between the volatility of the equally-weighted commodity index and the volatility of inflation (MOVE1M) is equal to $0.62(0.83)$ during recessions, compared to 0.26 (0.03) during expansions. With very few exceptions, similar conclusions can be drawn for the sectoral commodity sub-indices. These results are in line with the evidence of Gargano and Timmermann (2014) for commodity returns.

\subsection{Predictive Regressions}

We move a step further and explore the predictive ability of the various macroeconomic and financial risk measures, we estimate the following regressions

\footnotetext{
${ }^{10}$ The Phillips-Perron unit-root test (Phillips and Perron, 1988) rejects the null hypothesis of a unit-root at the $1 \%$ significance level for all series (p-values in parentheses). Therefore, even though most series are highly persistent there in no need to take first differences or to consider alternative econometric procedures for modeling volatility.

${ }^{11}$ As noted previously, the equally-weighted index accommodates the full set of 25 contracts after the late 1980s, and thus January 1990 is a reasonable starting point for our analysis. The same comovement analysis performed over the 1970-2015 period gave similar results.
} 
for commodity futures volatility:

$$
L R V_{t}=\alpha+\gamma X_{t-1}+\sum_{j=1}^{6} \beta_{j} L R V_{t-j}+\epsilon_{t}
$$

where: $L R V_{t}$ is the logarithm of commodity futures volatility of month $t$ (see Equation (1)) and $X_{t-1}$ is either the scalar value for the single variable regressions or the vector of values of the different predictors in the case of multiple regressions. ${ }^{12}$ To avoid spurious results due to the high persistence in volatility as discussed by Paye (2006), we include six lags of the dependent variable in the right side of Equation (4). The above set of regressions is estimated using as the dependent variable the logarithmic volatility of: the equally-weighted excess return commodity futures index, its four main sectoral sub-indices, and the GSCI(Eq) index. ${ }^{13}$ Newey and West (1987) corrected standard errors with twelve lags are employed for the estimations. We standardize both the dependent as well as the explanatory variables prior to the estimation by subtracting the sample mean and dividing by the sample standard deviation. We do this in order to facilitate comparability across coefficients of the different explanatory variables.

Estimation results are reported in Tables 4 to 9 . The column labeled $\Delta \bar{R}^{2}$ shows the change in the adjusted $R^{2}$ coefficient $\left(\bar{R}^{2}\right)$ by adding a specific variable

\footnotetext{
${ }^{12}$ In sections C.2 and C.3 of the online appendix we present results from two additional robustness checks. In the first one, we employ the level as opposed to the logarithm of volatility. In the second one, we repeat all estimations using the logarithm of the variance instead of the volatility. Both these tests provide similar and in some cases stronger results.

${ }^{13}$ One may argue that the volatility of sectoral commodity sub-indices is subject to seasonal variations and thus seasonal dummies or a periodic function should be included in Equation (4) to capture this behavior. Nevertheless, this is likely to be the case only for individual commodities, but not for commodity indices as some of the commodities contained in a given index are seasonal while others are not. As a consequence, the resulting volatility is not expected to exhibit any seasonal patterns. Indeed, when we include seasonal dummies in the predictive regressions for the four sectoral commodity sub-indices, as we find these dummies to be insignificant in all cases.
} 
to a sixth-order autoregressive specification which serves as a benchmark. Our main results are summarized as follows. Variables related to credit risk, funding illiquidity, equity and bond market stress, such as the default return spread, the TED spread, the VIX, and the MOVE1M index, are significant predictors of commodity market volatility. Among the core macroeconomic risk factors, only inflation volatility has some moderate predictive ability for commodity market volatility, which is mainly present in the early part of our sample. ${ }^{14}$ Furthermore, the ADS index has a negative and significant loading in the post-2004 sub-period, indicating that shocks in the real economy affect near-term commodity market volatility.

Interestingly, the predictive power of many of these predictors is concentrated in the post-financialization period, which also includes the 2008-2009 global financial crisis. This is evident from the substantial increase in explanatory power relative to the autoregressive benchmark model during this period. We shed further light on the dynamics of these predictive patterns in the following section.

The signs of the considered predictors are as expected. For example, the TED spread is positive and highly significant at the $5 \%$ level in the post-financialization period. This positive sign can be understood in the context of Brunnermeier et al. (2008), where a higher TED spread is associated with greater funding illiquidity (and greater market stress), pushing the volatility of risky assets to higher levels. ${ }^{15}$ The negative sign of the ADS index of real business conditions is also intuitive, as it suggests that during bad economic times commodity futures' volatility tends to

\footnotetext{
${ }^{14}$ Results available in the supplementary appendix (Tables D.1-D.6) show that inflation risk is a stronger predictor of commodity market volatility before the 1990s, but its predictive ability diminishes thereafter.

${ }^{15}$ Büyükşahin and Robe (2014) identify the TED spread as a fundamental driver of stockcommodity return comovement.
} 
increase. In a similar fashion, the positive and significant coefficients of equity and bond market option-implied volatilities (i.e. VIX and MOVE1M indices) in the post-2004 period suggest potentially stronger cross-market linkages (Büyükşahin and Robe, 2014) and also indicate that commodity return volatility is strongly dependent on general financial market uncertainty.

Interesting results also emerge from the multiple regression estimations based on a combination of significant predictors (reported at the bottom of each table). These results suggest some time-variation in the impact of the various risk factors. In particular, the overall predictability at the aggregate market level is stronger in the post-2004 period, which includes several important events, such as the financialization of commodity markets (Tang and Xiong, 2012; Silvennoinen and Thorp, 2013) and the global financial crisis. For the aggregate commodity market index (GSCI(Eq) index) in Table 4 (Table 5), a combination of factors adds a $4.96 \%(4.55 \%)$ to the explanatory power of the benchmark AR(6) model in the post-2004 period compared to $2.39 \%(2.67 \%)$ in the earlier part of the sample. Furthermore, the F-stat. reported in the same tables clearly rejects the null hypothesis that all variables are jointly zero in almost every case, especially in the post-2004 sub-period. Looking at the results across sectoral commodity subindices (Tables 6 to 9), we observe that the predictability is stronger for the agriculturals and weakest for livestock and metals. These differences are not entirely unexpected due to the heterogeneity of commodities (Erb and Harvey, 2006). Furthermore, for all commodity sectors our results suggest a change in the impact of significant predictors over time.

To formally investigate whether the relationship of commodity market volatility with the various economic uncertainty factors changes after the financialization of commodity markets (Tang and Xiong, 2012), we perform 
a Chow (1960) breakpoint test using December 2003 as our pre-specified breakpoint. A significant statistic would indicate a non-linear impact of specific risk factors on commodity market volatility. We reject the null hypothesis of no break at the $10 \%$ significance level for several variables (rejections of the null are marked with the superscript ${ }^{a}$ in the last column of Tables 4-9). In addition, sequential Bai and Perron (1998) tests for unknown breaks support the presence of structural breaks in a narrow time window around December 2003. This gives further credence to our choice of the above breakpoint.

\subsection{The Dynamics of Predictability}

Our evidence above suggests time-variation in the impact of the various risk factors on commodity market volatility. To this end, we analyze the dynamics of this predictability in a rolling regression context. Specifically, we estimate Equation (4) using the first 8 years of monthly observations, then move one month forward and repeat the estimation until the end of our sample. ${ }^{16}$ We assess the in-sample predictive performance by comparing the adjusted $R^{2}$ of each model with that of the benchmark autoregressive model:

$$
\Delta \bar{R}_{I S, t}^{2}=\bar{R}_{U, t}^{2}-\bar{R}_{R, t}^{2}
$$

where: $\Delta \bar{R}_{I S, t}^{2}$ is the month $t$ difference between the adjusted $R^{2}$ of the model augmented with a specific predictor $\left(\bar{R}_{U, t}^{2}\right)$, and the adjusted $R^{2}$ of the sixth-order autoregressive benchmark $\left(\bar{R}_{R, t}^{2}\right)$. Positive values indicate an improvement relative to the benchmark. Differences are expressed as a percentage (i.e.

\footnotetext{
${ }^{16}$ To make sure that the window length of 8 years chosen above is not the primary driver of our results we repeat the analysis using rolling samples of 10 and 12 years of data, respectively, and draw very similar conclusions. These results are available on request.
} 
multiplied by 100).

Figure 2 presents plots of the predictive performance for a selected set of variables used for predicting the volatility of the equally-weighted commodity market index. A notable feature of the plots is that the predictive ability of many risk factors substantially increases in the post-financialization period (i.e. after 2004) and reaches its peak around the 2008-2009 global financial crisis period. For example, the default return spread, the TED spread, and the MOVE1M exhibit significant predictive gains following the outbreak of the financial crisis. In some cases, this forecast improvement persists for prolonged periods (e.g. for the MOVE1M and the default return spread). Focusing on the macroeconomic volatility series (Inflation and IP), we observe that their predictive power is generally low in the post-2000 sub-sample with the exception of a period shortly before the onset of the global financial crisis. Finally, the model involving a combination of variables (bottom right graph) shows a persistent improvement in predictive power following the outburst of the crisis, which ranges between $6 \%$ and $12 \%$.

In sum, our analysis shows that a great deal of the documented predictability is concentrated in the 2008-2009 crisis. Even though this is a new result in commodities, earlier studies from the equity literature find that a fair amount of the predictability of returns and volatility is concentrated around recessions (Henkel et al., 2011; Paye, 2012). This result seems to suggest that variables that capture variation in credit risk, financial market risk or illiquidity may become increasingly important during bad times. 


\section{Conclusions}

In this paper, we investigate the links between economic uncertainty and commodity market volatility. We show that commodity market volatility comoves with economic and financial uncertainty and that this comovement is much stronger during recessions. We also estimate predictive regressions to explore the ability of a set of theoretically motivated economic variables to predict commodity market volatility. We identify new predictors of commodity market volatility related to credit risk, funding liquidity risk, equity and bond market uncertainty and variation in real business conditions. We find evidence of a structural change in the predictive ability of the risk factors after 2004 a period that coincides with the so-called financialization of commodity markets.

Our analysis also reveals time-variation in the impact of the various predictors. Specifically, analyzing the dynamics of predictability over time, we find that the reported predictive gains increase substantially during the 2007-2009 global financial crisis and in some cases persist for long time periods. This finding is in line with evidence from the equity markets that predictability is concentrated in bad times (e.g. Henkel et al., 2011; Cujean and Hasler, 2017). Nevertheless, the observed pattern is not consistent across all variables, implying a potentially more complex relationship between economic uncertainty and commodity futures' volatility. Finally, we find that a simple combination of significant predictors leads to a substantial forecast improvement relative to a simple autoregressive benchmark, especially in the period following the onset of the global financial crisis. 


\section{References}

Andersen, T., Bollerslev, T., Diebold, F., and Labys, P. (2003). Modeling and forecasting realized volatility. Econometrica, 71(2):579-625.

Andersen, T. G., Bollerslev, T., Diebold, F. X., and Ebens, H. (2001). The distribution of realized stock return volatility. Journal of Financial Economics, 61(1):43-76.

Areal, N. M. and Taylor, S. J. (2002). The realized volatility of FTSE-100 futures prices. Journal of Futures Markets, 22(7):627-648.

Aruoba, S. B., Diebold, F. X., and Scotti, C. (2009). Real-time measurement of business conditions. Journal of Business and Economic Statistics, 27(4):417427 .

Bai, J. and Perron, P. (1998). Estimating and testing linear models with multiple structural changes. Econometrica, 66(1):47-78.

Bailey, W. and Chan, K. (1992). Macroeconomic influences and the variability of the commodity futures basis. Journal of Finance, 48(2):555-573.

Bansal, R., Khatchatrian, V., and Yaron, A. (2005). Interpretable asset markets? European Economic Review, 49(3):531-560.

Beltratti, A. and Morana, C. (2006). Breaks and persistency: Macroeconomic causes of stock market volatility. Journal of Econometrics, 131(1):151-177.

Bessembinder, H. (1992). Systematic risk, hedging pressure, and risk premiums in futures markets. Review of Financial Studies, 5(4):637-667.

Brunnermeier, M., Nagel, S., and Pedersen, L. (2008). Carry trades and currency crashes. Working Paper, NBER.

Büyükşahin, B. and Robe, M. A. (2014). Speculators, commodities and crossmarket linkages. Journal of International Money and Finance, 42:38-70.

Carr, P. and Wu, L. (2009). Variance risk premiums. Review of Financial Studies, 22(3):1311-1341.

Chow, G. C. (1960). Tests of equality between sets of coefficients in two linear regressions. Econometrica, 28(3):591-605.

Christiansen, C., Schmeling, M., and Schrimpf, A. (2012). A comprehensive look at financial volatility prediction by economic variables. Journal of Applied Econometrics, 27(6):956-977. 
Corsi, F. (2009). A simple approximate long-memory model of realized volatility. Journal of Financial Econometrics, 7(2):174-196.

Creti, A., Joëts, M., and Mignon, V. (2013). On the links between stock and commodity markets' volatility. Energy Economics, 37:16-28.

Cujean, J. and Hasler, M. (2017). Why does return predictability concentrate in bad times? The Journal of Finance, 72(6):2717-2758.

De Roon, F., Nijman, T., and Veld, C. (2000). Hedging pressure effects in futures markets. Journal of Finance, 55(3):1437-1456.

Degiannakis, S. and Filis, G. (2017). Forecasting oil price realized volatility using information channels from other asset classes. Journal of International Money and Finance, 76:28-49.

Engle, R. F., Ghysels, E., and Sohn, B. (2013). Stock market volatility and macroeconomic fundamentals. Review of Economics and Statistics, 95(3):776797.

Erb, C. and Harvey, C. (2006). The strategic and tactical value of commodity futures. Financial Analysts Journal, 62(2):69-97.

Gargano, A. and Timmermann, A. (2014). Forecasting commodity price indexes using macroeconomic and financial predictors. International Journal of Forecasting, 30(3):825-843.

Geman, H. and Nguyen, V. (2005). Soybean inventory and forward curve dynamics. Management Science, 51(7):1076-1091.

Gorton, G. and Rouwenhorst, K. (2006). Facts and fantasies about commodity futures. Financial Analysts Journal, 62(2):47-68.

Gorton, G. B., Hayashi, F., and Rouwenhorst, K. G. (2013). The fundamentals of commodity futures returns. Review of Finance, 17(1):35-105.

Hamilton, J. and Lin, G. (1998). Stock market volatility and the business cycle. Journal of Applied Econometrics, 11(5):573-593.

Henkel, S. J., Martin, J. S., and Nardari, F. (2011). Time-varying short-horizon predictability. Journal of Financial Economics, 99(3):560-580.

Hong, H. and Yogo, M. (2012). What does futures market interest tell us about the macroeconomy and asset prices? Journal of Financial Economics, 105(3):473490. 
Issler, J. V., Rodrigues, C., and Burjack, R. (2014). Using common features to understand the behavior of metal-commodity prices and forecast them at different horizons. Journal of International Money and Finance, 42:310-335.

Ludvigson, S. C. and Ng, S. (2009). Macro factors in bond risk premia. Review of Financial Studies, 22(12):5027-5067.

Merton, R. C. (1973). An intertemporal capital asset pricing model. Econometrica: Journal of the Econometric Society, pages 867-887.

Newey, W. and West, K. (1987). A simple positive semi-definite, heteroskedasticity and autocorrelation consistent covariance matrix. Econometrica, $55(3): 703-708$.

Ornelas, J. R. H. and Mauad, R. B. (2017). Volatility risk premia and future commodity returns. Journal of International Money and Finance, forthcoming.

Paye, B. (2006). Do macroeconomic variables predict aggregate stock market volatility? Working Paper, Rice University.

Paye, B. S. (2012). 'déjà vol': Predictive regressions for aggregate stock market volatility using macroeconomic variables. Journal of Financial Economics, 106(3):527-546.

Phillips, P. and Perron, P. (1988). Testing for a unit root in time series regression. Biometrika, 75(2):335-346.

Schwert, G. W. (1989). Why does stock market volatility change over time? Journal of Finance, 44(5):1115-53.

Silvennoinen, A. and Thorp, S. (2013). Financialization, crisis and commodity correlation dynamics. Journal of International Financial Markets, Institutions and Money, 24:42-65.

Singleton, K. J. (2014). Investor flows and the 2008 boom/bust in oil prices. Management Science, 60(2):300-318.

Tang, K. and Xiong, W. (2012). Index investment and the financialization of commodities. Financial Analysts Journal, 68(5):54-74.

Zhou, H. (2009). Variance risk premia, asset predictability puzzles, and macroeconomic uncertainty. Working paper. Federal Reserve Board. 
Panel A: Logarithmic Volatility of the Equally-Weighted Index

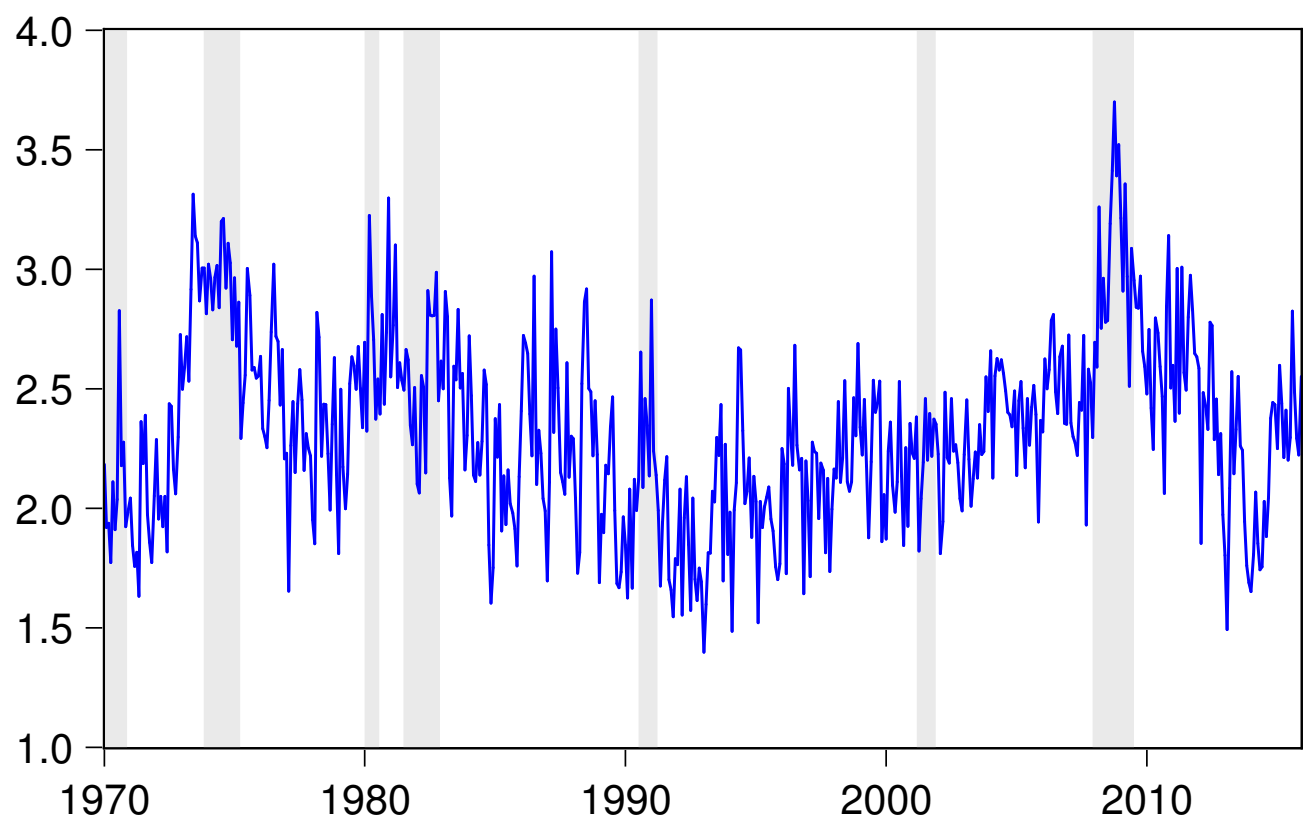

Panel B: Logarithmic Volatility of the GSCI(Eq) Index

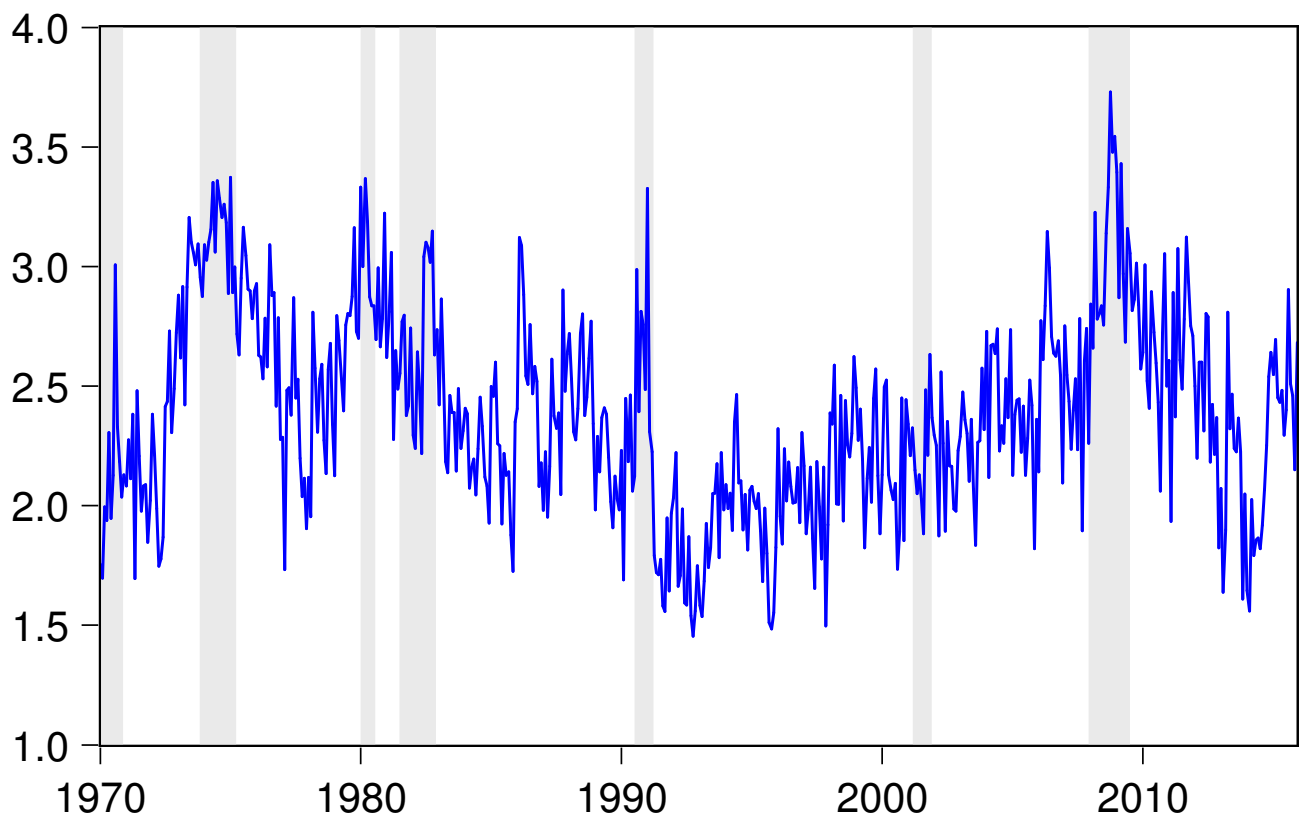

Figure 1: Commodity Market Volatility over the Business Cycle

This figure displays time series plots of the logarithm of realized volatility for the equally-weighted excess return commodity market index (Panel A) and the GSCI(Eq) excess return index (Panel B) over a period from January 1970 to December 2015. Gray shaded bars on the plot correspond to NBER recession periods. 

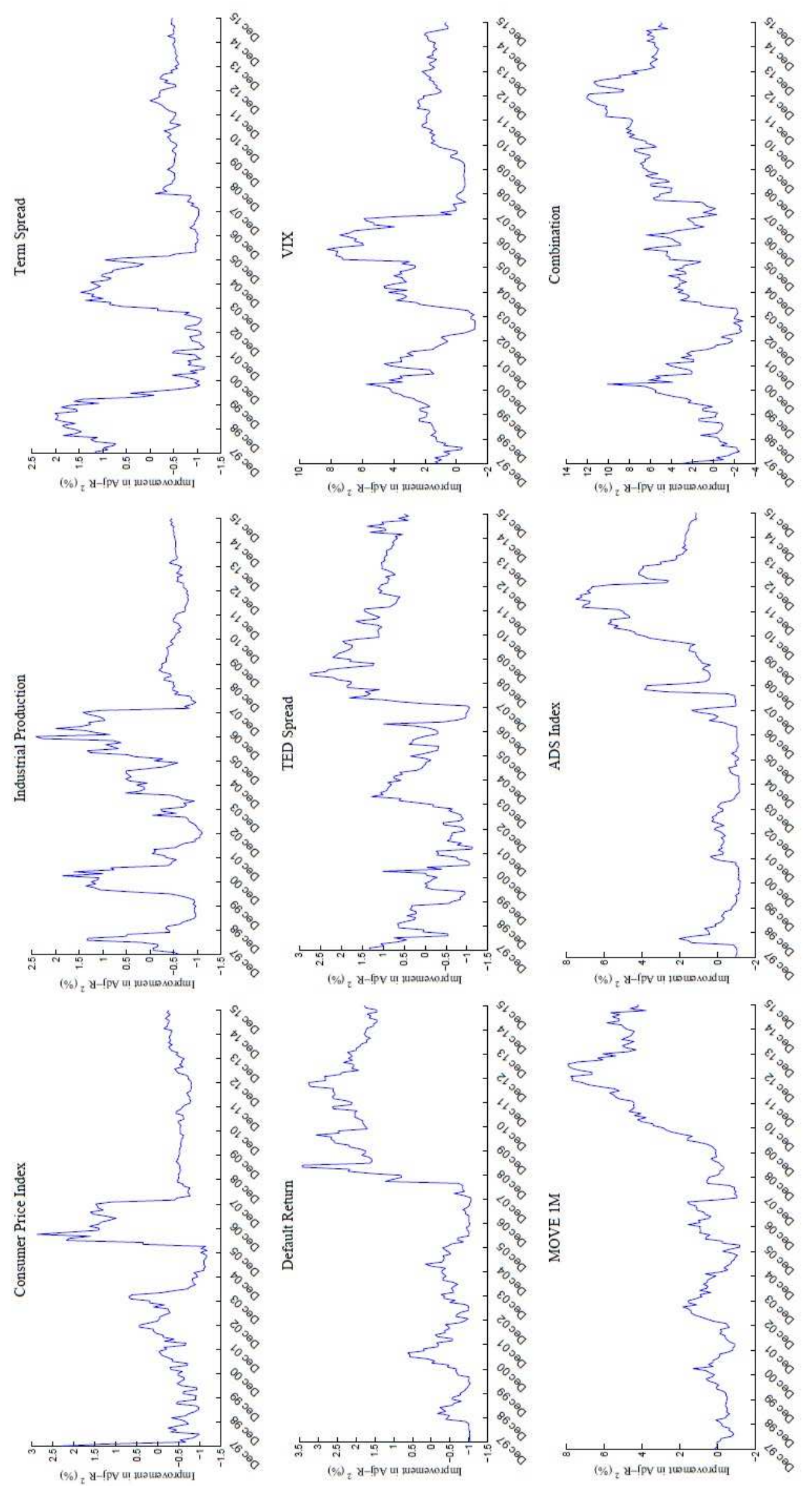

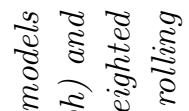

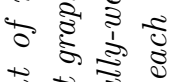

芯芯胥

कृष

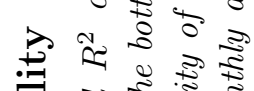

元

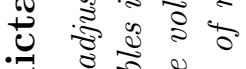

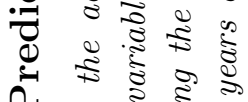

प. 0 के

पू

ส]

สู

ดั

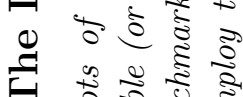

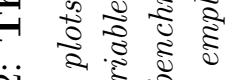

ن

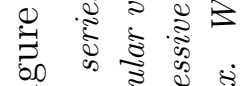

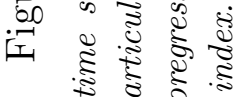

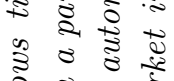

का है है है

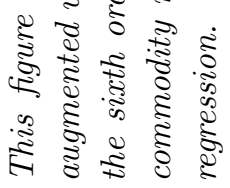




\section{Table 1: Details on Commodity Futures}

This table contains details on the commodity futures used to construct the equally-weighted excess return commodity futures index and its corresponding sectoral sub-indices. All futures data are obtained from the Commodity Research Bureau (CRB). The end date is December 31, 2015 for all commodities. CBOT: Chicago Board of Trade, CME: Chicago Mercantile Exchange, COMEX: Commodity Exchange, ICE: Intercontinental Exchange, NYMEX: New York Mercantile Exchange.

\begin{tabular}{llcc}
\hline \hline Group & Commodity & Start date & Exchange \\
\hline Agricultural & & & \\
& Cocoa & $06 / 07 / 1959$ & ICE \\
& Coffee & $17 / 08 / 1972$ & ICE \\
& Corn & $06 / 07 / 1959$ & CBOT \\
& Cotton & $06 / 07 / 1959$ & ICE \\
& Lumber & $02 / 10 / 1969$ & CME \\
& Oats & $06 / 07 / 1959$ & CBOT \\
& Orange juice & $02 / 02 / 1967$ & ICE \\
& Rough rice & $06 / 07 / 1987$ & CBOT \\
& Soybean meal & $06 / 07 / 1959$ & CBOT \\
& Soybean oil & $06 / 07 / 1959$ & CBOT \\
& Soybeans & $06 / 07 / 1959$ & CBOT \\
& Sugar & $04 / 01 / 1961$ & ICE \\
& Wheat & $06 / 07 / 1959$ & CBOT \\
& & & \\
Livestock & Feeder cattle & $01 / 12 / 1971$ & CME \\
& Lean hogs & $01 / 03 / 1966$ & CME \\
& Live cattle & $01 / 12 / 1964$ & CME \\
& & & \\
& Crude oil (WTI) & $31 / 03 / 1983$ & NYMEX \\
& Heating oil & $05 / 09 / 1979$ & NYMEX \\
& Gasoline & $02 / 01 / 1985$ & NYMEX \\
& Natural gas & $05 / 04 / 1990$ & NYMEX \\
& & \\
& Copper & $06 / 07 / 1959$ & COMEX \\
& Gold & $02 / 01 / 1975$ & COMEX \\
& Palladium & $04 / 01 / 1977$ & COMEX \\
& Platinum & $05 / 03 / 1968$ & COMEX \\
& Silver & $05 / 01 / 1965$ & COMEX \\
\hline \hline
\end{tabular}




\section{Table 2: Summary Statistics of Explanatory Variables}

This table presents summary statistics for the explanatory variables considered in our analysis. We employ monthly observations over the period from July 1959 to December 2015. The mean, median, standard deviation, skewness, and kurtosis are reported for each series along with the autocorrelation coefficients of orders 1 and 12 (labeled $\rho_{1}$ and $\rho_{12}$, respectively). The table also displays Phillips-Perron (1988) unit-root test statistics (PP column) with their associated p-values in parentheses. All volatility series are annualized and expressed as a percentage.

\begin{tabular}{|c|c|c|c|c|c|c|c|c|}
\hline Variable & Mean & Median & Std. Dev. & Skew. & Kurt. & $\rho_{1}$ & $\mathbf{P P}$ & Obs. \\
\hline Inflation vol. & 0.706 & 0.628 & 0.339 & 1.624 & 6.356 & 0.971 & $0.296-4.091(0.00)$ & 552 \\
\hline IP vol. & 2.038 & 1.892 & 0.792 & 1.325 & 4.942 & 0.959 & $0.229-4.362(0.00)$ & 552 \\
\hline M2 vol. & 0.917 & 0.845 & 0.375 & 1.157 & 4.314 & 0.959 & $0.300-4.187(0.00)$ & 552 \\
\hline USD index vol. & 6.011 & 5.704 & 2.573 & 1.051 & 5.644 & 0.579 & $0.252-14.092(0.00)$ & 516 \\
\hline Default yield spread & 1.100 & 0.960 & 0.452 & 1.748 & 6.979 & 0.962 & $0.427-3.893(0.00)$ & 552 \\
\hline Term spread & 2.070 & 2.255 & 1.473 & -0.685 & 3.377 & 0.949 & $0.471-4.253(0.00)$ & 552 \\
\hline Default return spread & 0.005 & 0.055 & 1.495 & -0.444 & 10.086 & -0.069 & $0.019-25.148(0.00)$ & 552 \\
\hline TED spread & 0.593 & 0.482 & 0.434 & 1.886 & 8.691 & 0.896 & $0.511-4.548(0.00)$ & 360 \\
\hline CFNAI & -0.019 & 0.055 & 1.019 & -1.138 & 6.436 & 0.663 & $0.076-12.014(0.00)$ & 552 \\
\hline VIX & 19.876 & 18.235 & 7.555 & 1.682 & 7.374 & 0.841 & $0.384-5.007(0.00)$ & 312 \\
\hline MOVE1M & 98.365 & 97.500 & 24.316 & 0.973 & 6.007 & 0.877 & $0.331-4.650(0.00)$ & 333 \\
\hline ADS & -0.091 & 0.007 & 0.884 & -1.253 & 6.882 & 0.872 & $0.078-6.170(0.00)$ & 552 \\
\hline VRP & 16.969 & 14.017 & 20.916 & -3.791 & 55.319 & 0.264 & $0.061-14.392(0.00)$ & 312 \\
\hline
\end{tabular}




\section{Table 3: Comovement Analysis}

This table presents pairwise correlation coefficients between commodity market volatility and economic and financial uncertainty measures. Columns 2-3 report correlations for the two aggregate commodity market indices, whereas the remaining four columns (4-7) contain results for sectoral sub-indices. Correlation coefficients that are not significant at the $5 \%$ level are marked with a dagger $(\dagger)$. The sample period is from January 1990 to December 2015. Panel I shows results for the full period, while Panels II and III present correlations during NBER expansions and recessions, respectively.

\begin{tabular}{|c|c|c|c|c|c|c|}
\hline & Eqw. Index & $\operatorname{GSCI}(\mathbf{E q})$ & Agricultural & Livestock & Energy & Metals \\
\hline \multicolumn{7}{|l|}{ I. Full sample } \\
\hline Inflation vol. & 0.505 & 0.527 & 0.358 & 0.160 & 0.448 & 0.434 \\
\hline IP vol. & 0.536 & 0.515 & 0.437 & 0.213 & 0.398 & 0.382 \\
\hline M2 vol. & 0.263 & 0.274 & 0.217 & $0.105^{\dagger}$ & 0.174 & 0.253 \\
\hline USD index vol. & 0.594 & 0.588 & 0.496 & 0.219 & 0.378 & 0.537 \\
\hline Default yield spread & 0.665 & 0.677 & 0.515 & 0.301 & 0.461 & 0.497 \\
\hline Term spread & 0.135 & $0.088^{\dagger}$ & 0.175 & $0.103^{\dagger}$ & $-0.077^{\dagger}$ & $0.072^{\dagger}$ \\
\hline Default return spread & $-0.078^{\dagger}$ & $-0.060^{\dagger}$ & $-0.047^{\dagger}$ & $0.081^{\dagger}$ & $-0.018^{\dagger}$ & -0.127 \\
\hline TED spread & 0.425 & 0.414 & 0.343 & $0.084^{\dagger}$ & 0.328 & 0.313 \\
\hline CFNAI & -0.537 & -0.559 & -0.413 & -0.157 & -0.451 & -0.405 \\
\hline VIX & 0.507 & 0.520 & 0.393 & 0.274 & 0.466 & 0.376 \\
\hline MOVE1M & 0.437 & 0.374 & 0.420 & 0.261 & 0.393 & 0.193 \\
\hline ADS & -0.564 & -0.581 & -0.438 & -0.194 & -0.467 & -0.427 \\
\hline VRP & -0.245 & -0.191 & -0.257 & $0.001^{\dagger}$ & $0.024^{\dagger}$ & -0.222 \\
\hline \multicolumn{7}{|l|}{ II. Expansions } \\
\hline Inflation vol. & 0.263 & 0.309 & $0.110^{\dagger}$ & $0.025^{\dagger}$ & 0.282 & 0.245 \\
\hline IP vol. & $0.090^{\dagger}$ & $0.063^{\dagger}$ & $0.065^{\dagger}$ & $0.110^{\dagger}$ & 0.144 & $-0.012^{\dagger}$ \\
\hline M2 vol. & 0.196 & 0.210 & 0.129 & $0.004^{\dagger}$ & $0.014^{\dagger}$ & 0.233 \\
\hline USD index vol. & 0.335 & 0.330 & 0.270 & 0.124 & 0.155 & 0.334 \\
\hline Default yield spread & 0.378 & 0.408 & 0.237 & 0.237 & 0.208 & 0.225 \\
\hline Term spread & $0.035^{\dagger}$ & $-0.018^{\dagger}$ & $0.105^{\dagger}$ & $0.056^{\dagger}$ & -0.184 & $-0.020^{\dagger}$ \\
\hline Default return spread & $0.023^{\dagger}$ & $0.002^{\dagger}$ & $0.053^{\dagger}$ & $0.007^{\dagger}$ & $0.063^{\dagger}$ & $-0.058^{\dagger}$ \\
\hline TED spread & $-0.112^{\dagger}$ & -0.120 & $-0.096^{\dagger}$ & $-0.045^{\dagger}$ & $0.041^{\dagger}$ & $-0.114^{\dagger}$ \\
\hline CFNAI & -0.140 & -0.171 & $-0.097^{\dagger}$ & $-0.042^{\dagger}$ & -0.119 & $-0.061^{\dagger}$ \\
\hline VIX & 0.226 & 0.243 & 0.149 & 0.203 & 0.273 & $0.101^{\dagger}$ \\
\hline MOVE1M & $0.029^{\dagger}$ & $-0.079^{\dagger}$ & 0.128 & 0.160 & 0.169 & -0.211 \\
\hline $\mathrm{ADS}$ & -0.161 & -0.192 & $-0.105^{\dagger}$ & $-0.096^{\dagger}$ & -0.135 & $-0.077^{\dagger}$ \\
\hline VRP & $-0.033^{\dagger}$ & $-0.003^{\dagger}$ & $-0.052^{\dagger}$ & $0.058^{\dagger}$ & 0.123 & $-0.073^{\dagger}$ \\
\hline \multicolumn{7}{|l|}{ III. Recessions } \\
\hline Inflation vol. & 0.615 & 0.609 & 0.522 & 0.473 & 0.459 & 0.582 \\
\hline IP vol. & 0.748 & 0.756 & 0.650 & 0.414 & 0.505 & 0.697 \\
\hline M2 vol. & $0.084^{\dagger}$ & $0.068^{\dagger}$ & $0.136^{\dagger}$ & $0.336^{\dagger}$ & $0.157^{\dagger}$ & $0.022^{\dagger}$ \\
\hline USD index vol. & 0.864 & 0.870 & 0.748 & 0.456 & 0.554 & 0.830 \\
\hline Default yield spread & 0.737 & 0.746 & 0.630 & 0.488 & 0.451 & 0.677 \\
\hline Term spread & 0.590 & 0.505 & 0.575 & 0.567 & $0.215^{\dagger}$ & 0.567 \\
\hline Default return spread & $-0.215^{\dagger}$ & $-0.153^{\dagger}$ & $-0.193^{\dagger}$ & 0.340 & $-0.156^{\dagger}$ & $-0.270^{\dagger}$ \\
\hline TED spread & 0.791 & 0.793 & 0.717 & $0.249^{\dagger}$ & 0.393 & 0.778 \\
\hline CFNAI & -0.666 & -0.670 & -0.550 & $-0.261^{\dagger}$ & -0.480 & -0.673 \\
\hline VIX & 0.695 & 0.702 & 0.591 & 0.427 & 0.514 & 0.717 \\
\hline MOVE1M & 0.833 & 0.823 & 0.763 & 0.549 & 0.460 & 0.788 \\
\hline $\mathrm{ADS}$ & -0.714 & -0.698 & -0.620 & $-0.312^{\dagger}$ & -0.483 & -0.716 \\
\hline VRP & -0.556 & -0.500 & -0.564 & $-0.154^{\dagger}$ & $-0.145^{\dagger}$ & -0.528 \\
\hline
\end{tabular}




\section{Table 4: Predictive Regressions for the Volatility of the Equally- Weighted Commodity Market Index}

This table presents results from predictive regressions of the logarithmic volatility of the equally-weighted excess return index on lagged macroeconomic and financial uncertainty variables. Panel I presents regressions against each variable, whereas Panel II shows results from multivariate estimations against a combination of variables. We report the results for the period from January 1990 to December 2015 as well as for two sub-periods: January 1990-December 2003 (pre-financialization period) and January 2004-December 2015 (post-financialization period). The intercept is not reported to save space. All variables are standardized prior to the estimations using the sample mean and standard deviation. For the single variable estimations we report the slope coefficient $(\gamma)$ along with the change in the adjusted $R^{2}$ (labeled $\Delta \bar{R}^{2}$ ) with respect to a simple $A R(6)$ benchmark specification that omits the specific variable. $\Delta \bar{R}^{2}$ is expressed in percentage terms (multiplied by 100). For the multivariate estimations, we show the F-statistic from testing the null hypothesis that all coefficients are jointly zero along with the increase in the $\bar{R}^{2}$ relative to the benchmark specification. Superscript ${ }^{a}$ indicates rejection of the null hypothesis of no structural break in December 2003 using a Chow (1960) test and a 10\% significance level. Newey-West corrected standard errors with 12 lags are employed for the estimations. *, **, and *** indicate significance at the 10\%, 5\% and 1\% level, respectively.

\begin{tabular}{|c|c|c|c|c|c|c|}
\hline & \multicolumn{2}{|c|}{$\begin{array}{l}\text { Full period } \\
\underline{1990-2015} \\
\end{array}$} & \multicolumn{2}{|c|}{$\begin{array}{c}\text { Sub-period } 1 \\
\underline{1990-2003}\end{array}$} & \multicolumn{2}{|c|}{$\begin{array}{c}\text { Sub-period } 2 \\
2004-2015\end{array}$} \\
\hline & $\gamma$ & $\Delta \bar{R}^{2}$ & $\gamma$ & $\Delta \bar{R}^{2}$ & $\bar{\gamma}$ & $\Delta \bar{R}^{2}$ \\
\hline \multicolumn{7}{|l|}{ I. Single Predictors } \\
\hline Inflation vol. & $0.099^{* *}$ & 0.370 & 0.108 & 0.487 & 0.071 & -0.085 \\
\hline IP vol. & 0.013 & -0.144 & -0.024 & -0.474 & 0.025 & -0.341 \\
\hline M2 vol. & 0.025 & -0.105 & 0.016 & -0.505 & 0.005 & -0.369 \\
\hline USD index vol. & 0.047 & 0.019 & 0.008 & -0.527 & 0.056 & -0.236 \\
\hline Default yield spread & 0.050 & -0.024 & 0.045 & -0.344 & 0.057 & -0.237 \\
\hline Term spread & -0.006 & -0.155 & -0.082 & 0.122 & 0.001 & -0.372 \\
\hline Default return spread & $-0.082^{* *}$ & 0.524 & 0.032 & -0.424 & $-0.137^{* * *}$ & 1.448 \\
\hline TED spread & 0.060 & 0.181 & 0.028 & -0.453 & $0.155^{* * *}$ & $1.368^{a}$ \\
\hline CFNAI & -0.078 & 0.328 & -0.032 & -0.430 & $-0.173^{*}$ & 1.350 \\
\hline VIX & 0.053 & 0.078 & $0.202^{* * *}$ & 2.551 & $0.132^{* *}$ & $0.549^{a}$ \\
\hline MOVE1M & 0.065 & 0.233 & $0.108^{*}$ & 0.617 & $0.286^{* * *}$ & $2.961^{a}$ \\
\hline ADS & $-0.095^{* *}$ & 0.533 & -0.036 & -0.402 & $-0.190^{* *}$ & $1.786^{a}$ \\
\hline VRP & -0.005 & -0.156 & $0.150^{* *}$ & 1.593 & -0.017 & $-0.346^{a}$ \\
\hline \multicolumn{7}{|l|}{ II. Multiple predictors } \\
\hline & F-stat & $\Delta \bar{R}^{2}$ & F-stat & $\Delta \bar{R}^{2}$ & F-stat & $\Delta \bar{R}^{2}$ \\
\hline Combined variables & $2.671^{* *}$ & 1.279 & $1.928^{*}$ & 2.390 & $3.995^{* * *}$ & 4.958 \\
\hline
\end{tabular}


Table 5: Predictive Regressions for the Volatility of the GSCI(Eq) Index

This table presents results from predictive regressions of the logarithmic volatility of the GSCI(Eq) index on lagged macroeconomic and financial uncertainty factors. Panel I presents regressions against each variable, whereas Panel II shows results from multivariate estimations against a combination of variables. We report the results for the period from January 1990 to December 2015 as well as for two sub-periods: January 1990-December 2003 (pre-financialization period) and January 2004-December 2015 (post-financialization period). The intercept is not reported to save space. All variables are standardized prior to the estimations using the sample mean and standard deviation. For the single variable estimations we report the slope coefficient $(\gamma)$ along with the change in the adjusted $R^{2}$ (labeled $\Delta \bar{R}^{2}$ ) with respect to a simple $A R(6)$ benchmark specification that omits the specific variable. $\Delta \bar{R}^{2}$ is expressed in percentage terms (multiplied by 100). For the multivariate estimations, we show the F-statistic from testing the null hypothesis that all coefficients are jointly zero along with the increase in the $\bar{R}^{2}$ relative to the benchmark specification. Superscript ${ }^{a}$ indicates rejection of the null hypothesis of no structural break in December 2003 using a Chow (1960) test and a 10\% significance level. Newey-West corrected standard errors with 12 lags are employed for the estimations. *, **, and *** indicate significance at the 10\%, 5\% and $1 \%$ level, respectively.

\begin{tabular}{|c|c|c|c|c|c|c|}
\hline & \multicolumn{2}{|c|}{$\begin{array}{l}\text { Full period } \\
1990-2015 \\
\end{array}$} & \multicolumn{2}{|c|}{$\begin{array}{c}\text { Sub-period } 1 \\
\text { 1990-2003 }\end{array}$} & \multicolumn{2}{|c|}{$\begin{array}{l}\text { Sub-period } 2 \\
2004-2015\end{array}$} \\
\hline & $\gamma$ & $\Delta \bar{R}^{2}$ & $\gamma$ & $\bar{\Delta} \bar{R}^{2}$ & $\gamma$ & $\Delta \bar{R}^{2}$ \\
\hline \multicolumn{7}{|l|}{ I. Single Predictors } \\
\hline Inflation vol. & $0.109^{* *}$ & 0.420 & 0.107 & 0.455 & 0.101 & 0.128 \\
\hline IP vol. & 0.013 & -0.132 & -0.049 & -0.190 & 0.084 & -0.044 \\
\hline M2 vol. & 0.011 & -0.136 & 0.010 & -0.415 & -0.035 & -0.312 \\
\hline USD index vol. & -0.007 & -0.141 & -0.045 & -0.216 & 0.069 & -0.206 \\
\hline Default yield spread & 0.056 & 0.007 & 0.044 & -0.270 & $0.149^{* *}$ & 0.392 \\
\hline Term spread & -0.022 & -0.095 & -0.101 & 0.572 & -0.009 & -0.403 \\
\hline Default return spread & $-0.084^{* *}$ & 0.536 & -0.007 & -0.421 & $-0.133^{* * *}$ & 1.342 \\
\hline TED spread & 0.018 & -0.114 & 0.007 & -0.421 & $0.142^{* *}$ & $1.093^{a}$ \\
\hline CFNAI & -0.076 & 0.290 & -0.045 & -0.232 & $-0.199^{* *}$ & $1.965^{a}$ \\
\hline VIX & 0.056 & 0.113 & $0.221^{* * *}$ & 3.099 & $0.131^{*}$ & $0.511^{a}$ \\
\hline MOVE1M & 0.027 & -0.075 & 0.021 & -0.383 & $0.244^{* *}$ & $2.466^{a}$ \\
\hline ADS & $-0.097^{* *}$ & 0.549 & $-0.084^{*}$ & 0.239 & $-0.191^{* *}$ & $1.866^{a}$ \\
\hline VRP & -0.005 & -0.143 & $0.190^{* *}$ & 2.838 & $-0.065^{*}$ & $-0.021^{a}$ \\
\hline \multicolumn{7}{|l|}{ II. Multiple predictors } \\
\hline & F-stat & $\Delta \bar{R}^{2}$ & F-stat & $\Delta \bar{R}^{2}$ & F-stat & $\Delta \bar{R}^{2}$ \\
\hline Combined variables & $2.671^{* *}$ & 1.175 & $2.314^{* *}$ & 2.665 & $3.439^{* * *}$ & 4.549 \\
\hline
\end{tabular}




\section{Table 6: Predictive Regressions for the Volatility of the Agricultural Futures Portfolio}

This table presents results from predictive regressions of the logarithmic volatility of the equally-weighted portfolio of agricultural futures on lagged macroeconomic and financial uncertainty factors. Panel I presents regressions against each variable, whereas Panel II shows results from multivariate estimations against a combination of variables. We report the results for the period from January 1990 to December 2015 as well as for two sub-periods: January 1990-December 2003 (pre-financialization period) and January 2004-December 2015 (post-financialization period). The intercept is not reported to save space. All variables are standardized prior to the estimations using the sample mean and standard deviation. For the single variable estimations we report the slope coefficient $(\gamma)$ along with the change in the adjusted $R^{2}$ (labeled $\Delta \bar{R}^{2}$ ) with respect to a simple $A R(6)$ benchmark specification that omits the specific variable. $\Delta \bar{R}^{2}$ is expressed in percentage terms (multiplied by 100). For the multivariate estimations, we show the F-statistic from testing the null hypothesis that all coefficients are jointly zero along with the increase in the $\bar{R}^{2}$ relative to the benchmark specification. Superscript ${ }^{a}$ indicates rejection of the null hypothesis of no structural break in December 2003 using a Chow (1960) test and a 10\% significance level. Newey-West corrected standard errors with 12 lags are employed for the estimations. *, **, and *** indicate significance at the 10\%, 5\% and 1\% level, respectively.

\begin{tabular}{|c|c|c|c|c|c|c|}
\hline & \multicolumn{2}{|c|}{$\begin{array}{l}\text { Full period } \\
1990-2015 \\
\end{array}$} & \multicolumn{2}{|c|}{$\begin{array}{l}\text { Sub-period } 1 \\
\underline{1990-2003}\end{array}$} & \multicolumn{2}{|c|}{$\begin{array}{c}\text { Sub-period } 2 \\
2004-2015\end{array}$} \\
\hline & $\gamma$ & $\Delta \bar{R}^{2}$ & $\gamma$ & $\Delta \bar{R}^{2}$ & $\bar{\gamma}$ & $\Delta \bar{R}^{2}$ \\
\hline \multicolumn{7}{|l|}{ I. Single Predictors } \\
\hline Inflation vol. & $0.127^{* * *}$ & 0.912 & $0.165^{* * *}$ & 1.996 & 0.033 & $-0.330^{a}$ \\
\hline IP vol. & 0.070 & 0.186 & -0.010 & -0.559 & 0.045 & $-0.290^{a}$ \\
\hline M2 vol. & $0.102^{* * *}$ & 0.718 & 0.024 & -0.505 & $0.106^{* *}$ & $0.531^{a}$ \\
\hline USD index vol. & 0.050 & 0.001 & -0.099 & 0.424 & 0.044 & $-0.304^{a}$ \\
\hline Default yield spread & $0.118^{* * *}$ & 0.677 & 0.008 & -0.561 & 0.068 & $-0.183^{a}$ \\
\hline Term spread & 0.033 & -0.100 & -0.076 & 0.000 & 0.025 & $-0.360^{a}$ \\
\hline Default return spread & $-0.073^{*}$ & 0.334 & -0.010 & -0.558 & $-0.127^{* *}$ & $1.215^{a}$ \\
\hline TED spread & 0.063 & 0.177 & 0.011 & -0.556 & $0.138^{* * *}$ & $1.126^{a}$ \\
\hline CFNAI & -0.072 & 0.231 & $0.083^{*}$ & 0.173 & $-0.158^{*}$ & $1.151^{a}$ \\
\hline VIX & $0.082^{* *}$ & 0.377 & $0.136^{* * *}$ & 1.230 & $0.174^{* * *}$ & $1.288^{a}$ \\
\hline MOVE1M & $0.088^{*}$ & 0.509 & 0.043 & -0.373 & $0.331^{* * *}$ & $4.243^{a}$ \\
\hline ADS & -0.073 & 0.237 & $0.107^{* *}$ & 0.673 & $-0.185^{* *}$ & $1.776^{a}$ \\
\hline VRP & 0.023 & -0.159 & $0.103^{*}$ & 0.503 & 0.033 & $-0.310^{a}$ \\
\hline \multicolumn{7}{|l|}{ II. Multiple predictors } \\
\hline & F-stat & $\Delta \bar{R}^{2}$ & F-stat & $\Delta \bar{R}^{2}$ & F-stat & $\Delta \bar{R}^{2}$ \\
\hline Combined variables & $2.863^{* *}$ & 1.886 & $3.354^{* * *}$ & 6.182 & $3.768^{* * *}$ & 5.123 \\
\hline
\end{tabular}




\section{Table 7: Predictive Regressions for the Volatility of the Livestock Futures Portfolio}

This table presents results from predictive regressions of the logarithmic volatility of the equally-weighted portfolio of livestock futures on lagged macroeconomic and financial uncertainty factors. Panel I presents regressions against each variable, whereas Panel II shows results from multivariate estimations against a combination of variables. We report the results for the period from January 1990 to December 2015 as well as for two sub-periods: January 1990-December 2003 (pre-financialization period) and January 2004-December 2015 (post-financialization period). The intercept is not reported to save space. All variables are standardized prior to the estimations using the sample mean and standard deviation. For the single variable estimations we report the slope coefficient $(\gamma)$ along with the change in the adjusted $R^{2}$ (labeled $\Delta \bar{R}^{2}$ ) with respect to a simple $A R(6)$ benchmark specification that omits the specific variable. $\Delta \bar{R}^{2}$ is expressed in percentage terms (multiplied by 100). For the multivariate estimations, we show the F-statistic from testing the null hypothesis that all coefficients are jointly zero along with the increase in the $\bar{R}^{2}$ relative to the benchmark specification. Superscript ${ }^{a}$ indicates rejection of the null hypothesis of no structural break in December 2003 using a Chow (1960) test and a 10\% significance level. Newey-West corrected standard errors with 12 lags are employed for the estimations. *, **, and *** indicate significance at the 10\%, 5\% and 1\% level, respectively.

\begin{tabular}{|c|c|c|c|c|c|c|}
\hline & \multicolumn{2}{|c|}{$\begin{array}{l}\text { Full period } \\
\underline{1990-2015} \\
\end{array}$} & \multicolumn{2}{|c|}{$\begin{array}{c}\text { Sub-period } 1 \\
\underline{1990-2003}\end{array}$} & \multicolumn{2}{|c|}{$\begin{array}{l}\text { Sub-period } 2 \\
2004-2015\end{array}$} \\
\hline & $\gamma$ & $\Delta \bar{R}^{2}$ & $\gamma$ & $\Delta \bar{R}^{2}$ & $\bar{\gamma}$ & $\Delta \bar{R}^{2}$ \\
\hline \multicolumn{7}{|l|}{ I. Single Predictors } \\
\hline Inflation vol. & 0.029 & -0.179 & 0.032 & -0.416 & -0.011 & -0.566 \\
\hline IP vol. & 0.056 & 0.014 & 0.049 & -0.287 & 0.068 & -0.239 \\
\hline M2 vol. & 0.017 & -0.226 & 0.072 & 0.015 & -0.073 & -0.027 \\
\hline USD index vol. & 0.076 & 0.268 & 0.125 & 1.058 & 0.040 & -0.467 \\
\hline Default yield spread & $0.091^{* *}$ & 0.462 & 0.039 & -0.381 & $0.126^{* * *}$ & 0.707 \\
\hline Term spread & 0.023 & -0.203 & 0.043 & -0.330 & 0.001 & -0.575 \\
\hline Default return spread & $-0.102^{* * *}$ & 0.811 & -0.061 & -0.138 & $-0.132^{* * *}$ & 1.169 \\
\hline TED spread & 0.047 & -0.025 & -0.057 & -0.183 & $0.124^{* * *}$ & 0.876 \\
\hline CFNAI & $-0.114^{* * *}$ & 1.037 & -0.057 & -0.191 & $-0.192^{* * *}$ & 2.648 \\
\hline VIX & 0.070 & 0.193 & 0.095 & 0.287 & 0.043 & -0.421 \\
\hline MOVE1M & 0.047 & -0.052 & 0.087 & 0.117 & 0.093 & 0.020 \\
\hline ADS & $-0.103^{* *}$ & 0.804 & -0.030 & -0.421 & $-0.194^{* * *}$ & 2.656 \\
\hline VRP & 0.009 & -0.247 & 0.071 & -0.053 & -0.008 & -0.568 \\
\hline \multicolumn{7}{|l|}{ II. Multiple predictors } \\
\hline & F-stat & $\Delta \bar{R}^{2}$ & F-stat & $\Delta \bar{R}^{2}$ & F-stat & $\Delta \bar{R}^{2}$ \\
\hline Combined variables & 1.393 & 0.592 & 0.747 & -0.788 & $2.090^{*}$ & 3.554 \\
\hline
\end{tabular}




\section{Table 8: Predictive Regressions for the Volatility of the Energy Futures Portfolio}

This table presents results from predictive regressions of the logarithmic volatility of the equally-weighted portfolio of energy futures on lagged macroeconomic and financial uncertainty factors. Panel I presents regressions against each variable, whereas Panel II shows results from multivariate estimations against a combination of variables. We report the results for the period from January 1990 to December 2015 as well as for two sub-periods: January 1990-December 2003 (pre-financialization period) and January 2004-December 2015 (post-financialization period). The intercept is not reported to save space. All variables are standardized prior to the estimations using the sample mean and standard deviation. For the single variable estimations we report the slope coefficient $(\gamma)$ along with the change in the adjusted $R^{2}$ (labeled $\Delta \bar{R}^{2}$ ) with respect to a simple $A R(6)$ benchmark specification that omits the specific variable. $\Delta \bar{R}^{2}$ is expressed in percentage terms (multiplied by 100). For the multivariate estimations, we show the F-statistic from testing the null hypothesis that all coefficients are jointly zero along with the increase in the $\bar{R}^{2}$ relative to the benchmark specification. Superscript ${ }^{a}$ indicates rejection of the null hypothesis of no structural break in December 2003 using a Chow (1960) test and a 10\% significance level. Newey-West corrected standard errors with 12 lags are employed for the estimations. *, **, and *** indicate significance at the 10\%, 5\% and 1\% level, respectively.

\begin{tabular}{|c|c|c|c|c|c|c|}
\hline & \multicolumn{2}{|c|}{$\begin{array}{l}\text { Full period } \\
1990-2015 \\
\end{array}$} & \multicolumn{2}{|c|}{$\begin{array}{c}\text { Sub-period } 1 \\
\underline{1990-2003} \\
\end{array}$} & \multicolumn{2}{|c|}{$\begin{array}{l}\text { Sub-period } 2 \\
2004-2015\end{array}$} \\
\hline & $\gamma$ & $\Delta \bar{R}^{2}$ & $\gamma$ & $\Delta \bar{R}^{2}$ & $\gamma$ & $\Delta \bar{R}^{2}$ \\
\hline \multicolumn{7}{|l|}{ I. Single Predictors } \\
\hline Inflation vol. & 0.081 & 0.248 & 0.127 & 0.731 & 0.103 & 0.121 \\
\hline IP vol. & 0.032 & -0.095 & -0.006 & -0.399 & 0.054 & -0.209 \\
\hline M2 vol. & -0.017 & -0.146 & 0.017 & -0.372 & -0.032 & -0.236 \\
\hline USD index vol. & 0.027 & -0.112 & -0.030 & -0.312 & 0.081 & 0.045 \\
\hline Default yield spread & 0.056 & 0.064 & 0.088 & 0.181 & 0.049 & -0.169 \\
\hline Term spread & $-0.063^{*}$ & 0.225 & $-0.118^{*}$ & 0.993 & -0.019 & -0.300 \\
\hline Default return spread & $-0.116^{* * *}$ & 1.137 & -0.067 & 0.048 & $-0.134^{* * *}$ & 1.383 \\
\hline TED spread & $0.084^{* *}$ & 0.487 & 0.012 & -0.387 & $0.133^{* * *}$ & 1.137 \\
\hline CFNAI & $-0.080^{* *}$ & 0.379 & -0.067 & 0.009 & $-0.092^{* *}$ & 0.349 \\
\hline VIX & $0.090^{*}$ & 0.465 & $0.249^{* *}$ & 3.302 & 0.026 & $-0.276^{a}$ \\
\hline MOVE1M & 0.072 & 0.272 & -0.038 & -0.255 & $0.142^{* * *}$ & 1.114 \\
\hline ADS & $-0.110^{* * *}$ & 0.850 & $-0.100^{*}$ & 0.548 & $-0.118^{* * *}$ & 0.738 \\
\hline VRP & 0.012 & -0.160 & $0.172^{* *}$ & 2.333 & $-0.071^{* * *}$ & $0.173^{a}$ \\
\hline \multicolumn{7}{|l|}{ II. Multiple predictors } \\
\hline & F-stat & $\Delta \bar{R}^{2}$ & F-stat & $\Delta \bar{R}^{2}$ & F-stat & $\Delta \bar{R}^{2}$ \\
\hline Combined variables & $3.528^{* * *}$ & 2.529 & $2.741^{* *}$ & 3.916 & $3.795^{* * *}$ & 4.986 \\
\hline
\end{tabular}


Table 9: Predictive Regressions for the Volatility of the Metals Portfolio

This table presents results from predictive regressions of the logarithmic volatility of the equally-weighted portfolio of metal futures on lagged macroeconomic and financial uncertainty factors. Panel I presents regressions against each variable, whereas Panel II shows results from multivariate estimations against a combination of variables. We report the results for the period from January 1990 to December 2015 as well as for two sub-periods: January 1990-December 2003 (pre-financialization period) and January 2004-December 2015 (post-financialization period). The intercept is not reported to save space. All variables are standardized prior to the estimations using the sample mean and standard deviation. For the single variable estimations we report the slope coefficient $(\gamma)$ along with the change in the adjusted $R^{2}$ (labeled $\Delta \bar{R}^{2}$ ) with respect to a simple $A R(6)$ benchmark specification that omits the specific variable. $\Delta \bar{R}^{2}$ is expressed in percentage terms (multiplied by 100). For the multivariate estimations, we show the F-statistic from testing the null hypothesis that all coefficients are jointly zero along with the increase in the $\bar{R}^{2}$ relative to the benchmark specification. Superscript ${ }^{a}$ indicates rejection of the null hypothesis of no structural break in December 2003 using a Chow (1960) test and a 10\% significance level. Newey-West corrected standard errors with 12 lags are employed for the estimations. *, **, and *** indicate significance at the 10\%, 5\% and 1\% level, respectively.

\begin{tabular}{|c|c|c|c|c|c|c|}
\hline & \multicolumn{2}{|c|}{$\begin{array}{l}\text { Full period } \\
\underline{1990-2015} \\
\end{array}$} & \multicolumn{2}{|c|}{$\begin{array}{c}\text { Sub-period } 1 \\
\underline{1990-2003} \\
\end{array}$} & \multicolumn{2}{|c|}{$\begin{array}{c}\text { Sub-period } 2 \\
2004-2015\end{array}$} \\
\hline & $\gamma$ & $\Delta \bar{R}^{2}$ & $\gamma$ & $\Delta \bar{R}^{2}$ & $\gamma$ & $\Delta \bar{R}^{2}$ \\
\hline \multicolumn{7}{|l|}{ I. Single Predictors } \\
\hline Inflation vol. & 0.078 & 0.249 & -0.093 & 0.347 & $0.171^{* *}$ & $1.509^{a}$ \\
\hline IP vol. & -0.004 & -0.177 & $-0.168^{* *}$ & 1.905 & 0.078 & $-0.090^{a}$ \\
\hline M2 vol. & -0.011 & -0.168 & -0.075 & 0.045 & -0.019 & $-0.470^{a}$ \\
\hline USD index vol. & 0.067 & 0.174 & -0.013 & -0.511 & 0.148 & $0.906^{a}$ \\
\hline Default yield spread & 0.036 & -0.091 & -0.087 & 0.250 & $0.131^{*}$ & $0.490^{a}$ \\
\hline Term spread & 0.006 & -0.176 & -0.064 & -0.148 & -0.004 & $-0.494^{a}$ \\
\hline Default return spread & $-0.088^{* * *}$ & 0.592 & $-0.096^{*}$ & 0.407 & $-0.101^{* *}$ & $0.486^{a}$ \\
\hline TED spread & 0.039 & -0.037 & 0.042 & -0.366 & $0.123^{* *}$ & $0.793^{a}$ \\
\hline CFNAI & -0.072 & 0.282 & -0.062 & -0.140 & $-0.157^{*}$ & $1.250^{a}$ \\
\hline VIX & 0.041 & -0.023 & 0.069 & -0.055 & $0.168^{*}$ & $1.445^{a}$ \\
\hline MOVE1M & 0.008 & -0.172 & -0.101 & 0.501 & $0.168^{* *}$ & $1.586^{a}$ \\
\hline ADS & $-0.078^{*}$ & 0.355 & -0.062 & -0.129 & $-0.150^{*}$ & $1.172^{a}$ \\
\hline VRP & -0.031 & -0.083 & 0.102 & 0.479 & -0.016 & $-0.471^{a}$ \\
\hline \multicolumn{7}{|l|}{ II. Multiple Predictors } \\
\hline & F-stat & $\Delta \bar{R}^{2}$ & F-stat & $\Delta \bar{R}^{2}$ & F-stat & $\Delta \bar{R}^{2}$ \\
\hline Combined variables & 1.939 & 0.661 & 1.459 & 0.951 & $2.667^{* *}$ & 3.122 \\
\hline
\end{tabular}

